\title{
NEW MENBRANES MADE OF SINTERED CLAY APPLICATION TO CROSSFLOW MICROFILTRATION
}

\author{
BENTAMA Jilali*, OUAZZANI Kamar, ELGAROUANI Abdelaziz \\ * Laboratory of the Processes and the Environment \\ High School of Technology \\ P.O. Box: 2427 Fez Morocco
}

\begin{abstract}
The new mineral membranes made of sintered clay are performed and characterized in terms of porosity, hydraulic resistance, pore diameter and mechanical resistance. It is shown that these membranes can be used as microfiltration membrane. The variations of the filtrate flux as a function of time are measured during the crossflow microfiltration operation of dilute suspensions of bentonite and talc, for different transmembrane pressure values and mean flow rates. Four membranes of different porosities are tested. The crossflow microfiltration of a biologic fluid model is realized in a membrane bioreactor. We showed that according to the average pores diameter, this new clay membranes could have used in different applications; treatment of waters or to be integrated into a bioreactor.
\end{abstract}

Keywords: Clay; Membranes; crossflow microfiltration; Membrane bioreacteur

\section{INTRODUCTION}

It is now commonly admitted that crossflow filtration processes can be considered as high performance separation techniques in many industrial applications such as food and beverage manufacture, biotechnology, wastewater treatment and drinking water production [13]. The membranes generally used in these processes can be classified in two groups corresponding to the nature of the material: organic or mineral. This paper concerns the characterization of new sintered clay microfiltration membranes. Four membranes of different porosity are elaborated. The tests of tangential filtration are made on suspensions model of bentonite or talc. The results of the filtration tests of water rich in dissolved organic matter and in suspension are turned out important for directing the clayey membranes to the treatment of waters. The results are reported in terms of filtrate flux as a function of time for the different membranes used. Four membranes of different porosities are tested. The coupling fermentation-microfiltration is tested with two clay membranes.

\section{RESEARCHMETHODOLOGY}

\section{Characteristics of the sintered clay Membranes}

This work is a part of a more complete study concerning clay material valorization [4]. The chemical composition of the clay used in this study (table 1) was determined by spectrometry atomic absorption, after fusion in the borate of strontium [5]. It is essentially constituted by silica, alumina and oxide of calcium (about $72 \%$ ). Besides, the contents in oxide alkaline are weak and the presence of the iron oxide (4,92\%) explains the rusts colour of the clay.

Table 1: Chemical composition of clay

\begin{tabular}{|l|l|l|l|l|l|l|l|l|l|l|}
\hline oxide & $\mathrm{SiO}_{2}$ & $\mathrm{Al}_{2} \mathrm{O}_{3}$ & $\mathrm{CaO}$ & $\mathrm{Fe}_{2} \mathrm{O}_{3}$ & $\mathrm{MgO}$ & $\mathrm{Na}_{2} \mathrm{O}$ & $\mathrm{K}_{2} \mathrm{O}$ & $\mathrm{TiO}_{2}$ & $\mathrm{MnO}$ & $\mathrm{SO}_{3}$ \\
\hline$\%$ & 47.05 & 10.34 & 14.53 & 04.92 & 03.91 & 01.40 & 01.73 & 0.55 & 0.05 & 0.57 \\
\hline
\end{tabular}

The characteristics of the sintered clay membranes used are given in table 2 . The different porosities are obtained by controlling the addition of a certain quantity of organic 
matter to the mixture before the sintering operation [6]. We chose four formulations: 5, 10, 15 and $20 \%$ agent of porosity represented respectively by $\mathrm{C}_{5}, \mathrm{C}_{10}, \mathrm{C}_{15}$ and $\mathrm{C}_{20}$.

Table 2: Characteristics of the membranes

\begin{tabular}{|l|c|c|c|c|}
\hline \multicolumn{1}{|c|}{ Membrane } & $\mathbf{C}_{\mathbf{5}}$ & $\mathbf{C}_{\mathbf{1 0}}$ & $\mathbf{C}_{\mathbf{1 5}}$ & $\mathbf{C}_{\mathbf{2 0}}$ \\
\hline Mechanical resistance $(\mathrm{MPa})$ & 1.09 & 0.95 & 0.82 & 0.73 \\
\hline Mean pore diameter $(\mu \mathrm{m})$ & 1.1 & 1.31 & 1.93 & 3.7 \\
\hline Porosity $(\%)$ & 37 & 43 & 49 & 53 \\
\hline Hydraulic resistance (m/Pa.s) & $1.710^{-9}$ & $2.010^{-9}$ & $2.610^{-9}$ & $3.810^{-9}$ \\
\hline
\end{tabular}

The membranes are tubular; the inner and outer diameters are respectively equal to $15 \mathrm{~mm}$ and $20 \mathrm{~mm}$, the length is equal to $155 \mathrm{~mm}$. On the figure 1 we show one membrane obtained from sintered clay A specially designed module was built to test the membranes.

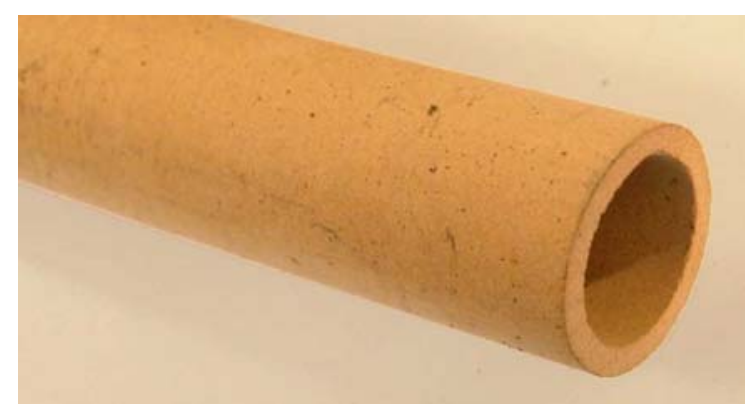

Figure 1. Membrane made of sintered clay

\section{EXPERIMENTALSET-UP}

The experimental apparatus (Figure 2) consists of a large fluid reservoir (4), a first volumetric pump (1) to ensure the circulation of the suspension, a second volumetric pump (2) for backflushing. Two pressure gauges (3) are used to measure the transmembrane pressure. The retentate is permanently recycled in the reservoir (4). The permeate is kept or used for backflushing. Two valves (6) allow us to control the flow rate and the pressure in the module in which the membrane is introduced (7).

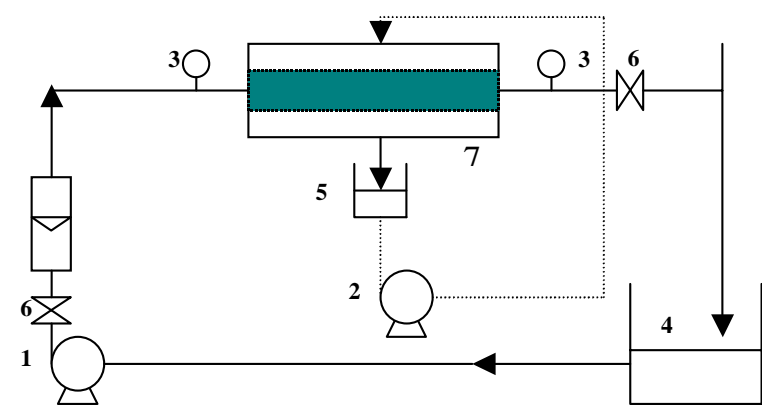

Figure 2. Experimental set-up

\section{RESULTSAND DISCUSION}

Various filtration operations are performed using the experimental set-up previously detailed. The operating conditions studied are: the nature of the suspension, the transmembrane pressure $(\Delta \mathrm{Ptm})$ and the flow rate (defined by the mean flow velocity $\mathrm{u}$ ). Ultrapure water is taken as the solvent.

\section{Bentonite suspension}

The mean size of bentonite particles is about 40 microns. The concentration of the suspension is $1 \mathrm{~g} / \mathrm{l}$. First, the effect of the transmembrane pressure on the filtrate flux magnitude is studied. As can be expected, the higher is the membrane porosity, the higher is the filtrate flux (Figure 3). Moreover, the gain in filtrate flux as the transmembrane pressure increases becomes progressive. It can be noticed that several authors $[7,8]$, have already evidenced the increase of the hydraulic resistance of the cake as the transmembrane pressure increases. This interesting phenomenon can be explained by the cake compression due to the particular shape of bentonite particles. The favorable effect of the flow rate on the filtrate flux magnitude has been also verified [9] (results not reported here) since the principle of the crossflow filtration is to take benefit of the existence of the wall shear stress to limit the cake formation.

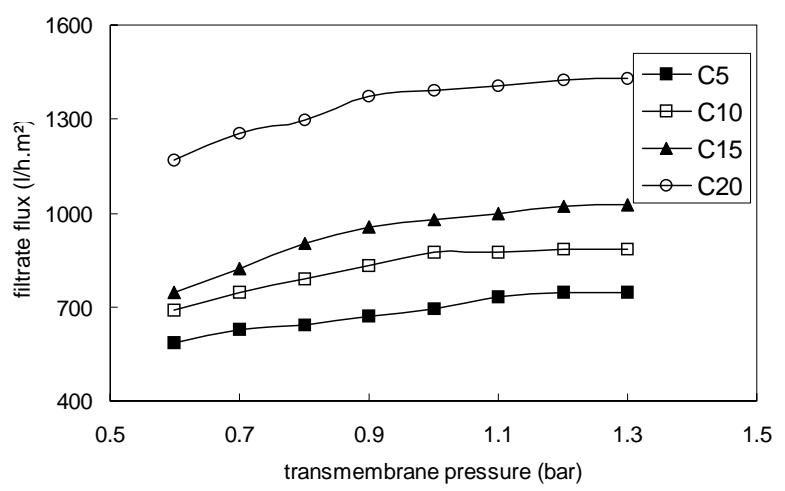

Figure 3. Effect of the transmembrane pressure on the filtrate flux; Bentonite suspension (1g/l); $u=1,47 \mathrm{~m} / \mathrm{s}$

\section{Talc suspension}

The mean size of talc particles is about 3 microns. The concentration of the suspension is $1 \mathrm{~g} / \mathrm{l}$. The turbidity of the filtrate is measured after each filtration operation and compared to the turbidity of the feeding suspension. Four membranes are tested; the results are reported in table 3. The corresponding reduction of the filtrate flux with time is plotted in Figure 4. It can be noticed that the shape of 
the curves for the membranes $\mathrm{C}_{5}$ and $\mathrm{C}_{10}$ are classical and that the associated turbidity drop rate is total. This result is in agreement with the pore diameter of these two membranes, which is inferior to the mean particle size. On the contrary, a more rapid decrease of filtrate flux is observed for the membranes $\mathrm{C}_{15}$ and $\mathrm{C}_{20}$ for which the pore diameter is superior to the mean particle size, In this case, the fouling of some pores of the membrane can occur, reducing its hydraulic resistance.

Table 3. Turbidity of the filtrate, filtration of talc

\begin{tabular}{|l|c|c|c|c|}
\hline Membrane & $\mathbf{C}_{\mathbf{5}}$ & $\mathbf{C}_{\mathbf{1 0}}$ & $\mathbf{C}_{\mathbf{1 5}}$ & $\mathbf{C}_{\mathbf{2 0}}$ \\
\hline Turbidity (N.T.U) & 0,95 & 0,95 & 10,32 & 61,07 \\
\hline Drop rate (\%) & 99,59 & 99,59 & 95,51 & 73,45 \\
\hline
\end{tabular}

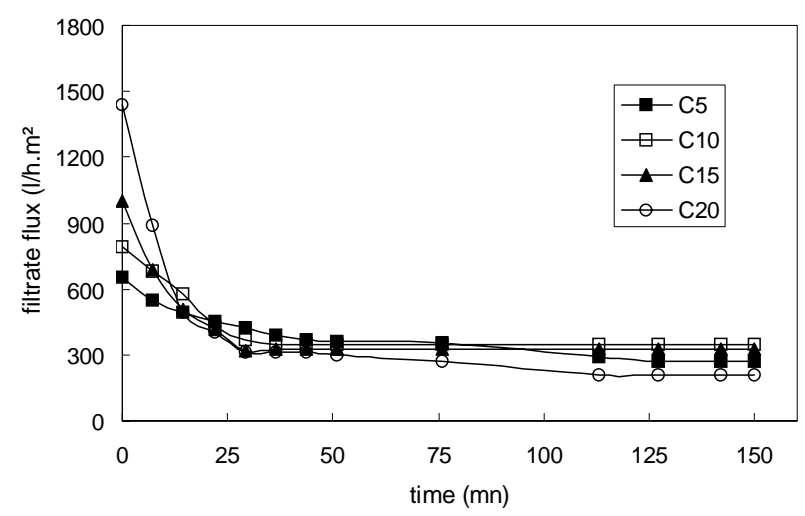

Figure 4. Effect the membrane porosity on the filtrate flux; Talc suspension (1g/l); $\Delta \mathrm{Ptm}=1 \mathrm{bar} ; \mathrm{u}=1,47 \mathrm{~m} / \mathrm{s}$

\section{Coupling fermentation-micofiltration tangential}

This technique presents the advantage of the continuous cultures, which allow to master the environment of cells and to achieve by the recycling the microorganisms with very high active concentrations [10,11]. The biologic fluid model used in different attempts of microfiltration is a suspension of yeast bakers in powder.

The preparation of the suspension consists in hydrating the yeast in some physiological water $\left(\mathrm{NaCl}, 9 \mathrm{~g} . \mathrm{l}^{-1}\right)$. The

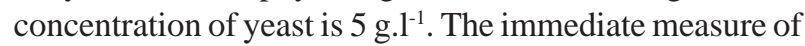
the concentration of yeast in the filtrate is made regularly by reading the optical density in $620 \mathrm{~nm}$ on a spectrophotometer.
On the figure 5, we present the evolution of the flux density according to time for membranes $\mathrm{C}_{10}$ and $\mathrm{C}_{15}$.

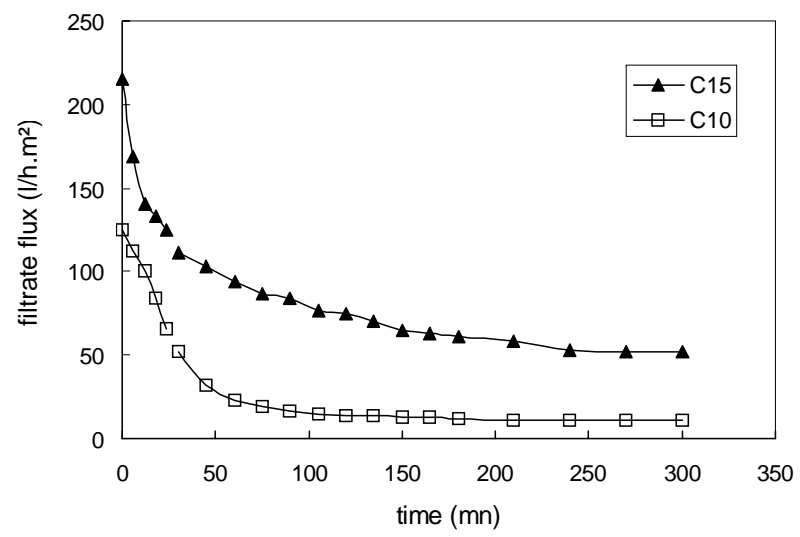

Figure 5. Effect the membrane porosity on the filtrate flux; Yeast suspension (5 g/l); $\Delta$ Ptm $=1$ bar; $u=1,47 \mathrm{~m} / \mathrm{s}$

Concerning the membrane $\mathrm{C}_{15}$, fast and important falls of the flux density followed by a slow and progressive fall are observed. The final value is stabilised after four hours. This profile is characteristic of the forming superficial layer in the immediate neighbourhood of the membrane. The filtration continues in the presence of this layer. It provokes a strong decrease of the actual diameter membrane pores. The second fall of the flux is due to the external sealing of the superficial layer. The evolution of the flux density according to time for the membrane $\mathrm{C}_{10}$ is characterized by an initial phase less short than that of the membrane $C_{15}$. After this phase, the flux stabilizes quickly. It confirms the absence of a progressive supplementary superficial layer in the neighbourhood of the membrane.

On the figure 6, we represent the evolution of the yeast concentration in the filtrate according to the time of filtration. The membrane $\mathrm{C}_{15}$ returns the concentration towards a value practically nobody expects in two stages (superficial layer and deposit of particle). A single fall of the yeast concentration in the filtrate is observed for the membrane $\mathrm{C}_{10}$ and after shorter time. For this type of application, microfiltration of a biologic fluid, the membrane $\mathrm{C}_{10}$ is recommended. 


\section{ACKNOWLEDGEMENTS}

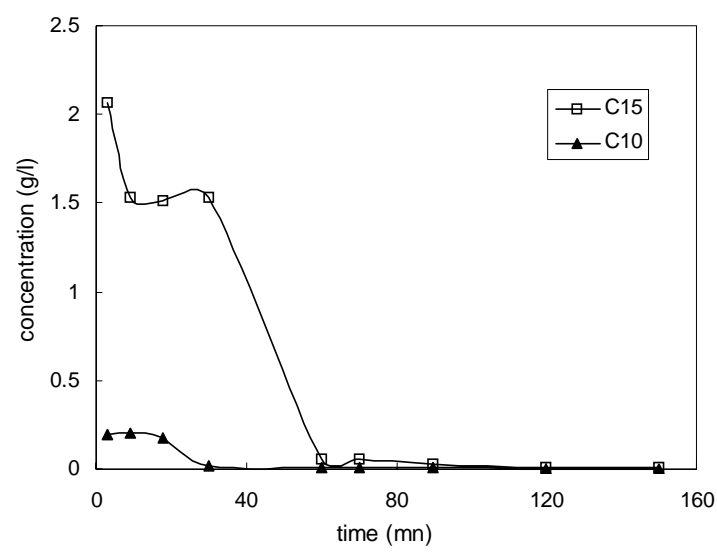

Figure 6. Effect the membrane porosity on the concentration; Yeast suspension (5 g/l); $\Delta \mathrm{Ptm}=1 \mathrm{bar} ; \mathrm{u}=$ $1,47 \mathrm{~m} / \mathrm{s}$

\section{CONCLUSION}

New mineral membranes made of sintered clay have been characterized and applied to the microfiltration of different suspensions. The filtrate flux variations as a function of the transmembrane pressure, the flow rate and the nature of the suspension have been analyzed. The compressibility of bentonite cake has been evidenced. We have also shown that the internal fouling of the membrane significantly reduced the filtrate flux and the backflushing is generally sufficient to recover the initial hydraulic resistance. Finally, we showed that according to the average pores diameter, the clay membranes could have different applications (treatment of waters or to be integrated into a bioreactor).
The “Comité Mixte Interuniversitaire Franco-Marocain” is gratefully acknowledged for its financial support $n^{\circ} 194 \mathrm{~F} /$ SI/99.

\section{REFERENCES}

[1] Davis R. H., Sherwood J. D. (1990). Chem. Eng. Sci., 45,p.3204.

[2] Rautenbach R. and Groschl A. (1990).Desalination, 77, p. 73.

[3] Pécorari M., and P. Bianco (1998). P. Electroanalysis, 10, p.181.

[4] Bentama J., Addaou, A., and Schmitz P. (2001) Récent Progrès en Génie des Procédés, (15) 81, p. 69.

[5] Jeanroy E. (1974) Analysis, 2 (10), p. 703.

[6] Bentama J., Addaou A., and Rafiq M. (1998). J. Chim. Phys., 5 (95), p.1001.

[7] Bauser H., Stroh N., Walitza E., and J. Membr. (1982). Sci.,11, p. 321.

[8] Tawell A., Landau J. and J. Chem (1976). Eng., , 54, p. 532.

[9] Bentama J., Schmitz P., (2000). $8^{\text {th }}$ Word filtration congress,Brighton UK, p. 435.

[10] Hsieh H.P. (1996). Membrane Science and Technology, Elsevier, Series 3, Amsterdam,.

[11] Hamdi M., Garcia G. L., Elloz R. Bioprocess Engineering., 1992, 8, p. 79. 